\title{
Mental Health, Academic Self-Efficacy and Study Progress Among College Students - The SHoT Study, Norway
}

\author{
Kirsti Grøtan ${ }^{1}$, Erik R. Sund ${ }^{1,2}$ and Ottar Bjerkeset ${ }^{1 *}$ \\ ${ }^{1}$ Faculty of Nursing and Health Sciences, Nord University, Levanger, Norway, ${ }^{2}$ HUNT Research Centre, Department of \\ Public Health and Nursing, Faculty of Medicine and Health Sciences, Norwegian University of Science and Technology \\ (NTNU), Levanger, Norway
}

OPEN ACCESS

Edited by:

Isabel Menezes,

Universidade do Porto, Portugal

Reviewed by:

Diana Aguiar Vieira

Polytechnic Institute of Porto,

Portugal

Fay Julal Cnossen

University of Birmingham,

United Kingdom

*Correspondence:

Ottar Bjerkeset

ottar.bjerkeset@nord.no

Specialty section:

This article was submitted to

Educational Psychology,

a section of the journal

Frontiers in Psychology

Received: 15 June 2018

Accepted: 08 January 2019

Published: 24 January 2019

Citation:

Grøtan K, Sund ER and

Bjerkeset O (2019) Mental Health,

Academic Self-Efficacy and Study

Progress Among College Students -

The SHoT Study, Norway.

Front. Psychol. 10:45.

doi: 10.3389/fpsyg.2019.00045
Student life can be stressful and for some students it may cause mental distress. Besides being a major public health challenge, mental distress can influence academic achievement. The main objectives of the current study were to examine associations of mental distress with academic self-efficacy and study progress. A secondary aim was to examine mental health help seeking for students with mental distress. Data was derived from the Norwegian Students' health and welfare survey 2014 (SHOT 2014) which is the first major survey comprising questions of both mental health, academic self-efficacy and psychosocial factors amongst students. Utilizing these data for a Norwegian region, we found that 749 (31\%) of the 2430 Norwegian full-time students under the age of 35 responded to the survey. Symptoms of mental distress were measured using the Hopkins Symptom Checklist (HSCL-25) and academic selfefficacy was measured using a Norwegian version of the General Self-Efficacy Scale (GSE) tailored to the academic setting. Demographic-, social, lifestyle, and study-related variables were included in the analyses. Logistic regression analyses were performed to assess the relationship between mental distress, academic self-efficacy, and academic performance. Seventeen percent reported severe symptoms of psychological distress which is similar to the overall prevalence among students in Norway. Students reporting severe mental distress were four times as likely to report low academic self-efficacy and twice as likely to report delayed study progress compared to students reporting few or moderate symptoms of mental distress. $27 \%$ of those reporting severe mental distress had sought professional help whereas 31\% had considered seeking help. The study showed that there was a strong association between symptoms of mental distress, academic self-efficacy and study progress. Prospective studies should evaluate whether improved help-seeking and psychological treatment can promote students mental health and ultimately improve academic self-efficacy and study progress.

Keywords: students, mental health, academic self-efficacy, study progress, help-seeking

\section{INTRODUCTION}

Today's younger generation represents the largest group of students in history. The transition from adolescence into young adulthood involves major changes in several areas - financial, housing, social, and emotional - and this transition period can cause relational challenges that some young adults experience as stressful. It has also been maintained that the proportion of students who 
experience their student life as mentally stressful is increasing (Nedregård and Olsen, 2014). This trend may suggest that students experience this period increasingly demanding, and for some of them it may be a direct cause of mental illness (Nerdrum et al., 2009).

Internationally, students' mental health is highlighted as a major public health challenge (Stallmann, 2008; Storrie et al., 2010). A systematic review found that half of the students who reported mental distress symptoms also had experienced these symptoms before they began their studies, while the remaining half developed symptoms during their studies. Other studies, from the United States, Canada, and United Kingdom, confirm high(er) rates of mental health problems among university students, compared to the general population in the same age group (Adalf et al., 2001; Bewick et al., 2010; Keyes et al., 2012). Mental distress has been linked to lower academic selfefficacy and poor study progress, yet underpinning mechanisms are complex and not fully elucidated. A longitudinal study from the United States found that mental health problems predicted delayed academic success (GPA), thus suggesting a direction of influence (Eisenberg et al., 2009). Further, there may be factors associated with both these factors operating on a number of levels, from individual factors to interpersonal issues and institutional characteristics. Of individual level factors, previous studies have reported that emotional problems had a negative effect on study progress and on the dropout rate from higher education (Robbins et al., 2004; Storrie et al., 2010).

Internationally, and particularly in the United States, a significant amount of research on the transition to higher education has been carried out over the last 40 years. This has contributed to development of a broader theoretical framework for understanding the factors important for college success. There are mainly two directions that points out this work; the sociological theories of education, such as Astin (1993) and Tinto (1993), and social cognitive learning theory by Bandura (1997) and Pascarella and Terenzini (2005). Astin emphasizes the importance of students taking part in the learning environment (Astin, 1993). Tinto further developed Astin's theories by emphasizing students' own driving forces as motivation, intentions, and adherence to education (Tinto, 1993).

Both anxiety and depression are detrimental to academic and social participation in everyday student life (Byrd and McKinney, 2012; Keyes et al., 2012; Salzer, 2012). Depressive disorders result in lowered mood, reduced cognitive function, lack of a sense of coping and interest in others, as well as lack of energy (Mykletun et al., 2009). In turn, depression and anxiety often affect memory and concentration, which makes it more difficult to acquire new knowledge and cope with examination situations. This will often reinforce perceptions of hopelessness and inadequacy, and in many people it will sustain the feeling of anxiety and depressed mood in a vicious circle (Rice et al., 2006; Stallmann, 2008). On the other hand, and depending on the symptom level, some uncertainty and anxiety in the academic situation may contribute to increased work effort and possibly improved results (Andrews and Wilding, 2004; Nedregård and Olsen, 2014).

The concept of self-efficacy refers to individuals' own beliefs about capabilities to organize and execute the courses of action required to produce given attainments (Bandura, 1997). In educational psychology research self-efficacy has been shown to predict Student's academic performance and progress across academic areas and levels (Pajares and Schunk, 2006; Vuong et al., 2010). Academic self-efficacy has been proven to be a powerful predictor when the critical performance is as global as the selfefficacy level measured (Choi, 2005; Zajacova et al., 2005). In studies of academic performance and persistence, social cognitive theory has proved to serve as a well-suited model (Brown et al., 2008).

Bandura's social cognitive learning theory emphasizes the inherent ability to develop control over thoughts, feelings, and actions. This approach focuses on cognitive processes in individual adaptation and interaction with the social environment, suggesting that poor social mastering reduces the capacity to build supportive social relationships (Bandura, 1997). A central concept is self-efficacy describing the individual's belief in their own coping in different situations. Low self-efficacy affects both achievements, ambitions, and motivation (Bandura, 1986; Dinther et al., 2011). Further, Bandura (1997) also linked experiences of persistent overthinking and negative self-esteem to the development of symptoms of anxiety and depression.

Also, students' ability to handle emotional stress during their studies was found to be an important factor in preventing academic delay and dropout (Storrie et al., 2010). In a review article based on studies among students in Australia, the authors reported that loneliness, also commonly linked to depression, was an independent risk factor for low study progress (Heinrich and Gullone, 2006). Other studies have reported that students have a number of concerns with their studies, with expectations about performing, and also report financial insecurities (Stewart-Brown et al., 2000; Stallmann, 2008).

The previous Students' Health and Welfare Survey in 2010 (SHoT 2010) showed that 25\% of students in Norway reported moderate or severe symptoms of mental health problems and $13 \%$ reported severe symptoms relating to mental health problems (Nedregård and Olsen, 2010). This is considerably higher than the rest of the population, where $12 \%$ in the same age group reported moderate or severe symptoms (Amdam and Vrålstad, 2012).

Compared to the general population and workforce, available knowledge about students' mental health is scarce. There is also insufficient knowledge about how mental health influences, or is influenced by academic progress. In addition, although Norwegian population based studies (Tyssen et al., 2004) and international student surveys (Zivin et al., 2009; Verouden et al., 2010; Eisenberg et al., 2012) report low mental health help seeking, we know little about the extent to which Norwegian students seek and receive appropriate mental health care.

We therefore examined the following research questions among college students participating in the SHoT study:

(1) How many of the students at a College in Norway report having severe mental health problems?

(2) Do students who report severe symptoms of mental health problems have a higher risk of low academic 
efficacy and poor study progress compared to students reporting few and moderate symptoms?

(3) To what extent do students at this College seek help for mental health problems?

\section{MATERIALS AND METHODS}

\section{Study Sample and Setting}

The Students' Health and Welfare Survey (SHoT) is a crosssectional questionnaire survey for Norwegian full-time students under the age of 35, conducted in February 2014 (Nedregård and Olsen, 2014). Students taking single courses and credit points that do not lead to a specific degree were excluded from the study. International students were also excluded from the study because previous SHoT studies in Trondheim and Oslo have shown that they are a heterogeneous group with challenges that differ considerably from those faced by Norwegian residents and/or citizens who are students (Nedregård and Olsen, 2014). Of all eligible students nationwide, a randomly drawn $10 \%$ sample were invited to SHoT. The only exception was this College, where all students in the total sample were invited. This decision was made by the student welfare association connected to the College to ensure that the sample was large enough to make it possible to process and interpret the data for this institution. Of a total of 20 invited Student Welfare Associations, 10 participated in SHoT 2014 , and together they represent $71 \%$ of all students in the target group (Nedregård and Olsen, 2014). Of a total of 47,514 students invited students nationally, 13,663 participated (29\%). At this College, 2,430 were invited, and 749 (31\%) participated. The share of women among participants was $69 \%$ and the corresponding figure among the invited was $62 \%$. With respect to age, $78.2 \%$ among the invited and $78.6 \%$ of the participants were in the age group 18-25.

\section{Data Collection}

An email with a link to the online questionnaire in Questback was sent to all students in the sample.

Most educational institutions gave access to both personal and student email addresses. At this University College, though, only student email addresses were used. In addition to the questionnaire, a cover letter was sent, informing the students that participation was voluntary and, among other details, that it was possible to leave some questions out. The link to the questionnaire was designed in a fashion that made it possible to save and return to the questionnaire several times, so no one felt pressured to complete it in one sitting. Data collection was conducted from 24th of February 2014 to 27th of March 2014. The Student Welfare Association helped market the survey using information material developed by the Communication department of the Student Welfare Associations. Information about SHoT was provided on the Student Welfare Association website and Facebook page, via student media, the University College's Facebook page, flyers and information stands at all campuses. To optimize the response rate, the Student Welfare Association offered a tablet computer and 10 gift certificates worth a total of $\mathrm{NOK} 3,000$ as prizes for use in the student association's facilities.

The formal agreement between the conductors and The Student Welfare Association described how personal data were processed, and all data were processed according to Norway's Personal Data Act.

\section{The Questionnaire in SHoT}

The questionnaire for SHoT 2014 is a revised version of the form used in SHoT 2010, which in turn was based on previous health and well-being studies among students in Oslo (HELT 2003 and 2005) and Trondheim (HOT 2004 and 2007) (Nedregård and Olsen, 2014).

The survey consists of 66 questions and instruments that assess the student's health and well-being; financial situation, housing, family situation, lifestyle, issues specific to studying as well as physical and mental health were all charted in the survey - with a particular emphasis on psychosocial issues. The conductors of the National survey designed the questionnaire in cooperation with the steering committee for SHoT, which included representatives from the Student Welfare Associations in Trondheim, Bergen, and Oslo (Nedregård and Olsen, 2014).

\section{Measurement Instruments HSCL-25 (Hopkins Symptom Checklist-25)}

Hopkins Symptom Checklist-25 is a widely used self-report instrument which measures several underlying dimensions of psychological distress, including anxiety and depression (Derogatis et al., 1974). In short, the HSCL-25 scale consists of two main subscales: a 10-item anxiety symptom scale and a 15-item depressive symptom Likert scales (Winokur et al., 1984; Tambs and Moum, 1993). Participants are asked to assess the subjective anxiety and depression symptom load in the past 2 weeks, and response categories were 'Not at all,' 'A little,' 'Quite a bit,' or 'Extremely.' Importantly, neither HSCL-25 nor other self-report instruments alone can be used to diagnose mental illness.

An average score above 1.75 indicates moderate to severe symptom load in the two last weeks and is often used as the cutoff point in scientific studies (Winokur et al., 1984; Tambs and Moum, 1993). In this study, however, a cut-off point at 2.0 is used and indicates a severe symptom load (Nedregård and Olsen, 2014).

To date, HSCL-25 has been utilized across various populations and settings; in psychiatric patients (Veijola et al., 2003), in the general population (Nyman et al., 2010), and in immigrants and minority groups (Mouanoutoua and Brown, 1995; Hoffmann et al., 2006). The psychometric properties of the HSCL-25 indicate adequate reliability and sensitivity of the subscales (Deane et al., 1992).

\section{GSE (General Self-Efficacy Scale)}

In SHoT 2014, academic self-efficacy was measured using a Norwegian version of the General Self-Efficacy Scale (GSE) (Jerusalem and Schwartzer, 1992), especially tailored to the academic setting. The GSE was adapted so that all the statements 
evaluate one's own efficacy as a student, rather than general trait self-efficacy (Nedregård and Olsen, 2014).

The GSE is based on the concept of self-efficacy derived from social cognitive learning theory, developed by Bandura (1997). The concept describes individuals' confidence in their own ability to cope with stress and various challenges.

The instrument consists of 10 statements on a fourpoint Likert-scale ranging from 1 ("completely wrong") to 4 ("completely correct"). Examples of statements included in the GSE:

'I can always manage to solve difficult problems in my studies if I try hard enough'

'If someone opposes me at school, I can find the means and ways to get what I want'

'It is easy for me to stick to my study aims and accomplish my goals.'

Average scores above 3.5 are defined as indicating high selfefficacy, scores between 2.5 and 3.5 are defined as average selfefficacy and scores under 2.5 as low self-efficacy (Nedregård and Olsen, 2014).

Results suggest that academic self-efficacy beliefs predict college outcomes but that this relationship is dependent on when efficacy beliefs are measured, the types of efficacy beliefs measured, and the nature of the criteria used (Gore, 2006).

\section{Study Progress}

In SHoT, the students were asked about their study progression in relation to nominal study length: 'Do you currently follow the nominal study progress in relation to nominal study length in the current semester (30 credits in one semester)?' Response options were: 'delayed,' 'not delayed,' or 'don't know.'

Of note, first semester students were excluded in the analyses of this question.

\section{Ethics Statement}

An invitation with a link to the questionnaire was sent out, and a cover letter was attached explaining the purpose of the study; participation was voluntary and participants could skip some of the questions if they did not want to answer them. All participants were adults and their consents were obtained by virtue of survey completion. The invitation also stated that data from the survey would be anonymized by the conductors of the survey, the email addresses would be deleted after the last reminders had been sent out and the winners of the incentives had been drawn. Those invited were also informed that the conductors of the survey had received approval from the Norwegian Centre for Research Data (NSD) to process the data and to anonymize them in accordance with Section 7-27 of the Personal Data Regulations, reported to NSD on 15 January 2014, case number 37102 (Nedregård and Olsen, 2014). This included access to, and analyses of anonymized data only. As part of the standard procedure, all e-mail addresses were deleted after the response, and before the database was established.

Hence, it was not necessary to obtain any additional written confirmed consent in this study. In cases where a written confirmed consent is required, NSD will refer the researcher/applicant to the Regional Committees for Medical and Health Research Ethics (REC), Norway ${ }^{1}$.

As a student counselor employed at the Student Welfare Association, the first author was actively involved in the information and recruitment campaign prior to SHoT 2014, at several campuses. It is uncertain if this may have affected participation, but there is little reason to believe that it has influenced the way that students answered the individual questions. The possibility to win prizes may also have influenced the students' willingness to participate in the investigation.

\section{Statistical Analysis}

Logistic regression models were specified whereby low academic efficacy and delayed academic performance were regressed on symptoms of mental distress in separate analyses (model 1). Subsequent models were built sequentially by adding likely confounding factors and finally adjusted for all (model 5). We did a complete case analysis and made no attempt to impute missing values on covariates. In the analysis of delayed academic performance, we discarded first-semester students $(N=79)$ since it was simply not possible for them to be delayed in their study progression at the time of survey. Excluded were also those who responded "don't know" on this question $(N=88)$. The net samples were thus 659 and 523 for low academic efficacy and delayed academic performance, respectively. We report odds ratios (OR) as our effect measure along with 95\% confidence intervals (95\% CI). Analyses were conducted in SPSS (v 22).

\section{RESULTS}

In SHoT 2014, a total of 2,430 full-time students at the College under the age of 35 were invited. Of these, 749 (31\%) answered the survey. Most of the respondents were women; in the total National sample $62.1 \%$ were women and at this College they accounted for $68.9 \%$ of participants (Nedregård and Olsen, 2014). Among the 749 participants at the College, 32\% reported symptoms of mental health problems of moderate or severe degree (cut-off 1.75 points) and $17 \%$ reported symptoms of severe mental health problems (cut-off 2.0 points) during the past 2 weeks (research question 1). In further analyses, 2.0 was used as the cut-off point for symptoms of mental health problems in this study.

Table 1 shows that almost half the participants were in the age group 18-25. In terms of marital/cohabitation status, 36\% lived with spouse/partner, $18 \%$ were in a relationship yet lived alone, and 45\% were single. Overall, 25\% lived alone. Only 13\% of the participants had children in their care, while more than $60 \%$ described themselves as financially vulnerable. Nearly $13 \%$ regarded themselves as lonely (socially and emotionally). As few as $7 \%$ stated that they smoked everyday, and about $6 \%$ drank alcohol more than twice per week. One in three (32\%) described themselves as physically inactive, and the same proportion spent $0-19 \mathrm{~h}$ per week on their studies.

\footnotetext{
${ }^{1}$ https://helseforskning.etikkom.no/forside?_ikbLanguageCode=us
} 
TABLE 1 | Sample characteristics, the SHoT survey $(N=749)$.

\begin{tabular}{|c|c|c|}
\hline & $N$ & $\%$ \\
\hline \multicolumn{3}{|l|}{ Demographic and social } \\
\hline \multicolumn{3}{|l|}{ Age group } \\
\hline $18-20$ & 154 & 20.6 \\
\hline $21-22$ & 232 & 31 \\
\hline $23-25$ & 203 & 27.1 \\
\hline $26-28$ & 83 & 11.1 \\
\hline $29+$ & 77 & 10.3 \\
\hline \multicolumn{3}{|l|}{ Gender } \\
\hline Female & 516 & 68.9 \\
\hline Male & 233 & 31.1 \\
\hline \multicolumn{3}{|l|}{ Marital status } \\
\hline Married/partner/cohabitant & 273 & 36.4 \\
\hline Romantic partner & 136 & 18.2 \\
\hline Single & 334 & 44.6 \\
\hline Missing & 6 & 0.6 \\
\hline \multicolumn{3}{|l|}{ Living alone } \\
\hline Yes & 184 & 24.6 \\
\hline No & 565 & 75.4 \\
\hline \multicolumn{3}{|l|}{ Caring for children } \\
\hline Yes & 96 & 12.8 \\
\hline No & 652 & 87 \\
\hline Missing & 1 & 0.1 \\
\hline \multicolumn{3}{|l|}{ Financially vulnerable } \\
\hline Yes & 294 & 60.5 \\
\hline No & 453 & 39.3 \\
\hline Missing & 2 & 0.3 \\
\hline \multicolumn{3}{|l|}{ Loneliness (social and emotional) } \\
\hline Yes & 93 & 12.4 \\
\hline No & 643 & 85.8 \\
\hline Missing & 13 & 1.7 \\
\hline \multicolumn{3}{|l|}{ Lifestyle } \\
\hline \multicolumn{3}{|l|}{ Daily smoker } \\
\hline Yes & 36 & 4.8 \\
\hline No & 693 & 92.5 \\
\hline Missing & 20 & 2.7 \\
\hline \multicolumn{3}{|l|}{ Alcohol use } \\
\hline$>=2$ times per week & 46 & 6.1 \\
\hline$<2$ times per week & 684 & 91.3 \\
\hline Missing & 19 & 2.5 \\
\hline \multicolumn{3}{|l|}{ Physical activity } \\
\hline Inactive & 240 & 32 \\
\hline Active & 480 & 64.1 \\
\hline Missing & 29 & 3.9 \\
\hline \multicolumn{3}{|l|}{ Academically related } \\
\hline \multicolumn{3}{|l|}{ Time spent on study (per week) } \\
\hline Over $40 \mathrm{~h}$ & 186 & 24.8 \\
\hline 20-39 h & 277 & 37 \\
\hline 0-19 h & 246 & 32.8 \\
\hline Missing & 40 & 5.3 \\
\hline \multicolumn{3}{|l|}{ Stage of study } \\
\hline 1st semester & 79 & 10.5 \\
\hline 2nd-3rd semester & 247 & 33 \\
\hline 4th-5th semester & 198 & 26.4 \\
\hline 6th-8th semester & 172 & 23 \\
\hline 9th+ semester & 41 & 5.5 \\
\hline Missing & 12 & 1.6 \\
\hline
\end{tabular}

TABLE 2 | Descriptives of outcomes and main predictor of interest, by gender.

\begin{tabular}{|c|c|c|c|c|c|c|}
\hline & \multicolumn{2}{|c|}{ Females } & \multicolumn{2}{|c|}{ Males } & \multicolumn{2}{|c|}{ Total } \\
\hline & $N$ & $\%$ & $N$ & $\%$ & $N$ & $\%$ \\
\hline \multicolumn{7}{|l|}{ Outcomes } \\
\hline \multicolumn{7}{|c|}{ Academic self-efficacy } \\
\hline Low & 75 & 14.6 & 29 & 12.4 & 104 & 13.9 \\
\hline Medium/high & 429 & 83.1 & 199 & 85.4 & 628 & 83.8 \\
\hline Missing & 12 & 2.3 & 5 & 2.2 & 17 & 2.3 \\
\hline \multicolumn{7}{|l|}{$\begin{array}{l}\text { Followed scheduled } \\
\text { study progress }\end{array}$} \\
\hline No & 30 & 5.8 & 16 & 6.9 & 46 & 6.1 \\
\hline Yes & 396 & 76.7 & 188 & 80.7 & 584 & 78.0 \\
\hline Don't know & 90 & 17.4 & 29 & 12.5 & 119 & 15.9 \\
\hline \multicolumn{7}{|c|}{ Main predictor of interest } \\
\hline \multicolumn{6}{|l|}{ Symptoms of mental } & distress (HSCL) \\
\hline Severe & 104 & 20.2 & 22 & 9.4 & 126 & 16.8 \\
\hline Few or moderate & 408 & 79.1 & 209 & 89.7 & 617 & 82.4 \\
\hline Missing & 4 & 0.8 & 2 & 0.9 & 6 & 0.8 \\
\hline
\end{tabular}

Table 2 shows that female students reported severe symptoms of mental health problems twice as frequently as male students, 20 and $10 \%$ respectively. In total, $14 \%$ reported low academic selfefficacy and $6 \%$ reported delayed study progress.

Table 3 shows bivariate relationships between various independent variables and the two dependent variables: low academic self-efficacy and delayed study progress. We found that the risk of experiencing low academic self-efficacy was more than four times higher [OR 4.55 (95\% CI 2.79-7.42)] among those who reported symptoms of severe mental health problems than among those who reported few and moderate symptoms.

Among students who reported loneliness (social and emotional), the odds of low academic self-efficacy were approximately 2.6 times higher [OR 2.6 (95\% CI 1.50-4.49)] than for those who did not report loneliness. Those who reported financial vulnerability had almost twice the risk [OR 1.85 (95\% CI 1.18-2.90)] of delayed study progress compared with the reference group (not financially vulnerable). Students who spent 20-30 h per week on their studies had a significantly lower risk [OR 0.48 (95\% CI 0.26-0.87)] while those who spent $0-19 \mathrm{~h}$ per week had a higher risk [OR 1.22 (95\% CI 0.72-2.08)] of reporting low academic self-efficacy compared with those who spent more than $40 \mathrm{~h}$ on their studies per week.

The odds of reporting delayed study progress was more than twofold increased [OR 2.47 (95\% CI 1.19-5.13)] for those with symptoms of severe mental health problems compared with those who reported few and moderate symptoms. The analyses also show a strong association between delayed study progress and loneliness, living alone, and physical inactivity, yet we found no sound statistical evidence for this.

Gender, age, marital status, living alone, and caring for children showed some association with both low academic self-efficacy and delayed study progress, but these were not statistically significant either (all $p$-values $>0.05$ ). 
TABLE 3 | Bivariate associations between various predictors and respective low academic self-efficacy and delayed study progress.

\begin{tabular}{|c|c|c|c|c|}
\hline & \multicolumn{2}{|c|}{$\begin{array}{l}\text { Low academic } \\
\text { self-efficacy }\end{array}$} & \multicolumn{2}{|c|}{$\begin{array}{l}\text { Delayed study } \\
\text { progress }\end{array}$} \\
\hline & OR & $95 \% \mathrm{Cl}$ & OR & $95 \% \mathrm{Cl}$ \\
\hline \multicolumn{5}{|c|}{ Symptoms of anxiety and depression (HSCL-25) } \\
\hline Few or moderate & 1 & Ref. & 1 & Ref. \\
\hline Severe & 4.55 & $(2.79-7.42)$ & 2.47 & $(1.19-5.13)$ \\
\hline \multicolumn{5}{|l|}{ Age groups } \\
\hline $18-22$ & 1 & Ref. & 1 & Ref. \\
\hline $23-25$ & 0.96 & $(0.57-1.64)$ & 1.58 & $(0.70-3.56)$ \\
\hline $26+$ & 0.92 & $(0.52-1.62)$ & 1.83 & $(0.81-4.15)$ \\
\hline \multicolumn{5}{|l|}{ Gender } \\
\hline Female & 1 & Ref. & 1 & Ref. \\
\hline Male & 0.76 & $(0.46-1.26)$ & 1.1 & $(0.55-2.22)$ \\
\hline \multicolumn{5}{|l|}{ Marital status } \\
\hline $\begin{array}{c}\text { Married/partner/ } \\
\text { cohabitant }\end{array}$ & 1 & Ref. & 1 & Ref. \\
\hline Romantic partner & 0.59 & $(0.29-1.20)$ & 0.81 & $(0.28-2.36)$ \\
\hline Single & 1.00 & $(0.62-1.61)$ & 1.22 & $(0.59-2.54)$ \\
\hline \multicolumn{5}{|l|}{ Living alone } \\
\hline No & 1 & Ref. & 1 & Ref. \\
\hline Yes & 1.02 & $(0.61-1.72)$ & 1.24 & $(0.58-2.63)$ \\
\hline \multicolumn{5}{|l|}{ Care for children } \\
\hline No & 1 & Ref. & 1 & Ref. \\
\hline Yes & 1.27 & $(0.68-2.37)$ & 1.05 & $(0.39-2.79)$ \\
\hline \multicolumn{5}{|l|}{ Financially vulnerable } \\
\hline No & 1 & Ref. & 1 & Ref. \\
\hline Yes & 1.85 & $(1.18-2.90)$ & 1.06 & $(0.54-2.10)$ \\
\hline \multicolumn{5}{|c|}{ Loneliness (social and emotional) } \\
\hline No & 1 & Ref. & 1 & Ref. \\
\hline Yes & 2.6 & $(1.50-4.49)$ & 1.96 & $(0.86-4.48)$ \\
\hline \multicolumn{5}{|l|}{ Physical activity } \\
\hline Active & 1 & Ref. & 1 & Ref. \\
\hline Inactive & 1.26 & $(0.80-2.01)$ & 1.55 & $(0.79-3.06)$ \\
\hline \multicolumn{5}{|c|}{ Time spent on study (per week) } \\
\hline Over $40 \mathrm{~h}$ & 1 & Ref. & 1 & Ref. \\
\hline 20-39 h & 0.48 & $(0.26-0.87)$ & 0.77 & $(0.35-1.70)$ \\
\hline $0-19 h$ & 1.22 & $(0.72-2.08)$ & 0.69 & $(0.29-1.65)$ \\
\hline \multicolumn{5}{|l|}{ Stage of study } \\
\hline 1st semester & 1.41 & $(0.66-3.02)$ & & \\
\hline 2nd-3rd semester & 1 & Ref. & 1 & Ref. \\
\hline 4th-5th semester & 1.39 & (0.78-2.49) & 0.27 & $(0.08-0.99)$ \\
\hline 6th-8th semester & 1.17 & $(0.64-2.14)$ & 1.43 & $(0.64-3.20)$ \\
\hline \multirow[t]{2}{*}{ 9th+ semester } & 0.64 & $(0.18-2.21)$ & 3.71 & $(1.40-9.84)$ \\
\hline & $N=659$ & & $N=523$ & \\
\hline
\end{tabular}

Odds ratio (OR) and $95 \%$ confidence interval $(95 \% \mathrm{Cl})$.

For research question 2, the multivariable regression analyses (Table 4) confirmed that symptoms of severe mental health problems were strongly associated with low academic selfefficacy; the crude odds ratio was robust to stepwise adjustment, and the final model (Model 5) still suggests a near fourfold increased risk [OR 3.82 (95\% CI 2.25-6.49)].

The variables loneliness, financial vulnerability and hours spent studying also showed a strong degree of association and were thus appropriate for inclusion in the multivariable analyses regarding low academic self-efficacy. Although the association between loneliness, living alone, physical inactivity and delayed study progress were not statistically significant, they were considered relevant for further inclusion in the analyses. The variables gender and age showed no statistically significant association with low academic self-efficacy and delayed study progress and they had no effect on the association between symptoms of mental health problems and the two outcomes. Table 5 indicates similar patterns for "delayed study progress"; the final model still showed a twofold increase in risk [OR 2.14 (95\% CI 0.97-4.72)] for students reporting severe psychological symptom levels, compared to mild or moderate levels (research question 2).

Addressing research question 3, Table 6 shows that one in four students with symptoms of severe mental health problems had sought help for these problems during the past 12 months. In the group with few and moderate problems, approximately $7 \%$ had sought help for psychological problems. In absolute numbers, however, more students have sought help in the group that reported few and moderate mental health problems than in the group reporting severe mental health problems. The analysis also revealed that in each group about the same number had not sought help but had considered doing so.

Overall, Table 6 confirms that men seek help for psychological problems to a lesser degree than women.

\section{DISCUSSION}

In the national SHoT survey for Norwegian colleges and universities in 2014 we examined the prevalence of mental health problems, their influence on academic self-efficacy and study progress, as well as self-reported help seeking for mental health problems. Overall, $17 \%$ of full-time students at this particular College reported symptoms of severe mental health problems, $14 \%$ reported low academic self-efficacy and $6 \%$ reported delayed study progress. Of those with symptoms of severe mental health problems, $27 \%$ had sought help for mental health problems, and $31 \%$ reported that they had considered this, but had not yet done so. Further, students who reported symptoms of severe mental health problems had four times the risk of low academic selfefficacy and twice the risk of delayed study progress, compared with those who reported few and moderate symptoms of mental health problems.

\section{Prevalence of Severe Mental Health Problems Among Students}

The prevalence of moderate and severe mental health problems among the students proved to be at about the same level as for the total sample in the national SHoT survey in 2014 (Nedregard and Olsen, 2014). Compared with the general Norwegian population in the same age group, using the same instruments, students report a twofold increased prevalence of symptoms of moderate and severe mental health problems (25 vs. $12 \%$, cut-off at 1.75) (Amdam and Vrålstad, 2012). This finding may indicate that there 
TABLE 4 | The risk of low academic self-efficacy among students.

\begin{tabular}{|c|c|c|c|c|c|c|c|c|c|c|}
\hline & \multicolumn{2}{|c|}{ Model 1} & \multicolumn{2}{|c|}{ Model 2} & \multicolumn{2}{|c|}{ Model 3} & \multicolumn{2}{|c|}{ Model 4} & \multicolumn{2}{|c|}{ Model 5} \\
\hline & OR & $95 \% \mathrm{Cl}$ & OR & $95 \% \mathrm{Cl}$ & OR & $95 \% \mathrm{Cl}$ & OR & $95 \% \mathrm{Cl}$ & OR & $95 \% \mathrm{Cl}$ \\
\hline Few or moderate & 1 & Ref. & 1 & Ref. & 1 & Ref. & 1 & Ref. & 1 & Ref. \\
\hline Severe & 4.55 & $(2.79-7.42)$ & 4.01 & $(2.40-6.69)$ & 4.28 & $(2.61-7.01)$ & 4.72 & $(2.87-7.79)$ & 3.82 & $(2.25-6.49)$ \\
\hline \multicolumn{11}{|c|}{ Social/emotional loneliness } \\
\hline \multicolumn{11}{|l|}{ Financially vulnerable } \\
\hline No & & & & & 1 & Ref. & & & 1 & Ref. \\
\hline Yes & & & & & 1.60 & $(1.00-2.55)$ & & & 1.75 & $(1.08-2.83)$ \\
\hline \multicolumn{11}{|c|}{ Hours spent on studies per week } \\
\hline More than 40 & & & & & & & 1 & Ref. & 1 & Ref. \\
\hline
\end{tabular}

Odds ratio (OR) and $95 \%$ confidence interval $(95 \% \mathrm{Cl}) . N=659$.

TABLE 5 | The risk of delayed study progress among students.

\begin{tabular}{|c|c|c|c|c|c|c|c|c|c|c|}
\hline & \multicolumn{2}{|c|}{ Model 1} & \multicolumn{2}{|c|}{ Model 2} & \multicolumn{2}{|c|}{ Model 3} & \multicolumn{2}{|c|}{ Model 4} & \multicolumn{2}{|c|}{ Model 5} \\
\hline & OR & $95 \% \mathrm{Cl}$ & OR & $95 \% \mathrm{Cl}$ & OR & $95 \% \mathrm{Cl}$ & OR & $95 \% \mathrm{Cl}$ & OR & $95 \% \mathrm{Cl}$ \\
\hline \multicolumn{11}{|c|}{ Symptoms of anxiety and depression (HSCL-25) } \\
\hline Few or moderate & 1 & Ref. & 1 & Ref. & 1 & Ref. & 1 & Ref. & 1 & Ref. \\
\hline Severe & 2.47 & $(1.19-5.13)$ & 2.22 & $(1.01-4.86)$ & 2.46 & $(1.19-5.11)$ & 2.35 & $(1.12-4.91)$ & 2.14 & $(0.97-4.72)$ \\
\hline \multicolumn{11}{|c|}{ Social/emotional loneliness } \\
\hline \multicolumn{11}{|l|}{ Living alone } \\
\hline No & & & & & 1 & Ref. & & & 1 & Ref. \\
\hline Yes & & & & & 1.21 & $(0.57-2.60)$ & & & 1.19 & $(0.56-2.56)$ \\
\hline \multicolumn{11}{|l|}{ Physical activity } \\
\hline Active & & & & & & & 1 & Ref. & 1 & Ref. \\
\hline
\end{tabular}

Odds ratio (OR) and $95 \%$ confidence interval $(95 \% \mathrm{Cl}) . N=523$.

TABLE 6 | Help-seeking behavior and symptoms of mental distress by gender.

\begin{tabular}{|c|c|c|c|c|c|c|c|c|c|c|c|c|c|}
\hline & \multicolumn{6}{|c|}{ Few/moderate symptoms } & \multicolumn{6}{|c|}{ Severe symptoms } & \multirow{2}{*}{ Grand Total } \\
\hline & \multicolumn{2}{|c|}{ Females } & \multicolumn{2}{|c|}{ Males } & \multicolumn{2}{|c|}{ Total } & \multicolumn{2}{|c|}{ Females } & \multicolumn{2}{|c|}{ Males } & \multicolumn{2}{|c|}{ Total } & \\
\hline Yes & 35 & 8.8 & 6 & 2.9 & 41 & 6.8 & 32 & 28.8 & 4 & 18.2 & 36 & 27.1 & $77(10.5 \%)$ \\
\hline No, but considered & 42 & 10.6 & 11 & 5.3 & 53 & 8.8 & 31 & 27.9 & 10 & 45.4 & 41 & 30.8 & $94(12.8 \%)$ \\
\hline
\end{tabular}

is something about academia and the study situation that makes students experience their study years as stressful, and for some this triggers mental illness (Adalf et al., 2001; Nerdrum et al., 2009).
The national results from SHoT 2014 also show that the total number of students reporting symptoms of severe mental health problems has increased compared with numbers from SHoT 2010 (Nedregård and Olsen, 2010). This is consistent 
with the overall trend among young adults in Norway from 2008 to 2012. In both studies, this is primarily explained by increased prevalence among women (Amdam and Vrålstad, 2012; Nedregård and Olsen, 2014).

In line with our findings, some international studies, where the same instruments have been used, confirm that students report mental health problems more often than non-students in the same age group (Roberts et al., 1999; Adalf et al., 2001; Stallmann, 2008; Ibrahim et al., 2013). At the same time, there are some major methodological differences between these studies, making direct comparison of results difficult. Further, samples sizes are all too often insufficient to establish sound statistical evidence (Cook et al., 2006).

Furthermore, we found that almost $13 \%$ of the students described themselves as lonely (socially and emotionally). The transition from living with family and having a social network that has been built up over time, to settling into new places, establish new friendships and integrating into new social communities, may be difficult for some students (Nerdrum et al., 2009; Eisenberg et al., 2012). In addition, the figures show that over $60 \%$ of the students describe themselves as financially vulnerable, which is in line with previous studies (Nerdrum et al., 2009; Eisenberg et al., 2013).

\section{Student Mental Health, Academic Self-Efficacy and Study Progress}

Our study indicates that students who report symptoms of severe mental health problems have about four times the risk of experiencing low academic self-efficacy compared with those who report few and moderate symptoms of mental health problems. A situation in which anxiety contributes to worries, motor restlessness, unfounded fear of not accomplishing things, in combination with procrastination and avoidance behavior, may contribute to students developing problems in participating actively in learning and study situations. This may in turn contribute to avoidance, isolation and loneliness, leading to poorer academic- and social inclusion with both fellow students and staff at the educational institution (Byrd and McKinney, 2012; Salzer, 2012). Our study shows that there is an association between mental health problems and academic self-efficacy, but we cannot make any claims about the causal direction. In exploring the relationship between psychosocial factors, study skills, and academic outcomes, the authors of a review study from the United States point out the lack of empirical studies that combine sociological education research and psychological theory in higher education (Robbins et al., 2004).

Tinto's research points to commitment as a particularly important factor in academic performance, best developed through professional and social participation facilitated by the educational institutions (Tinto, 2006). Students' experiences in the learning processes might give educational institutions a clearer picture of the factors that contribute to motivation and persistence (ibid; Reason et al., 2006).

In our study, students who reported symptoms of severe mental health problems were twice as likely to report delayed study progress compared with those who reported few and moderate mental health problems. However, there is little knowledge about the relationship between psychological distress and completion of credits among Norwegian students (Hovdhaugen and Aamodt, 2009). A review article that included 11 studies from three different countries, however, confirmed a clear association between poor emotional health and delayed study progress (Storrie et al., 2010). In addition, several international studies report a strong association between self-efficacy and academic performance (Robbins et al., 2004; Fenollar et al., 2007; Richardson et al., 2012).

In keeping with the literature, the authors of a Swedish longitudinal study reported a weak association between mental health and degree completion (Vaez and Laflamme, 2008). They found that low academic self-efficacy had a clear association with low completion of credits. In contrast, a cross-sectional study in the United States, in which clinical instruments were used to investigate the relationship between psychiatric diagnoses and academic performance, researchers found that generalized anxiety had a positive influence on academic performance (Svanum and Zody, 2001; Pritchard and Wilson, 2003). The fact that academic self-efficacy has been identified as a mediator between anxiety and academic performance, may help explain some contradictory results in different studies. Overall, though, they reported that mental health issues showed a weak, negative association with academic performance (Svanum and Zody, 2001). Further, they suggest that students' ability to cope with the academic situation depends, at least partly, on their understanding of and ability to handle emotional difficulties (Svanum and Zody, 2001). A meta-analytic investigation among Community College Students in the United States reported that anxiety seemed unrelated to both study persistence and college achievement, and that stress can impact both positively and negatively on students' achievements (Fong et al., 2017).

\section{Mental Health Help Seeking in College Students}

We found that $27 \%$ of the students with symptoms of severe mental health problems had sought help, while $31 \%$ had considered seeking help. Both Norwegian and international studies confirm that many students refrain from seeking help for psychological problems (Tyssen et al., 2004; Zivin et al., 2009; Verouden et al., 2010; Eisenberg et al., 2012). This is in keeping with evidence from the general population, which shows that low help seeking and under-treatment of anxiety and depression is pervasive and should receive more attention (Kessler et al., 2005; Roness et al., 2005).

The reasons students refrain from seeking help may be many and varied. A barrier to seeking help for psychological difficulties is that students want to be "normal" and not to stand out from the crowd, while others have the opinion that stress and difficulties are normal parts of a student's life (Verouden et al., 2010). Increased knowledge about support services on campus and interventions that reduce stigma would probably contribute to more students seeking help (Quinn et al., 2009; Storrie et al., 2010; Reavley and Jorm, 2010; Eisenberg et al., 2012). A review article based on studies mainly from the United States concludes 
that an effective way to reach students who need help, would be to offer interventions to a larger group of students (Regehr et al., 2013).

Educational institutions must have productive collaborative relationships, anchored in the whole institution, with counseling and health services both on campus and in the public health service to make it possible to offer effective help to students with serious mental health problems (Stanley and Manthorpe, 2001). Preventive initiatives at various levels and in various settings can raise the awareness of those who need help with their own problems and inform students about the support services that are available (Hunt and Eisenberg, 2010). Closer collaboration between the Student Welfare Association's counseling services, the educational institution and the public health service could also help increase the number of students who seek and are offered help, which in turn contribute to a better learning environment for all students (Storrie et al., 2010; Eisenberg et al., 2012).

Given the prevailing focus on the relationship between mental health, learning environment, social and academic affiliation and dropout from secondary education, it is paradoxical that this thinking receives little attention as a research question within higher education in Norway.

Among the help seekers at this college, only $23 \%$ had sought help from the Student Welfare Association's counseling services. In contrast, the three largest Norwegian universities located in Bergen, Trondheim and Oslo have the highest proportion of students seeking help from the counseling and health services of the Student Welfare Association, 58, 53, and 45\% respectively (not shown in Results). Importantly, an overview of the Student Welfare Association's health and counseling services shows that these universities offer a wider range of services with greater scope (including psychologists) than the smaller Student Welfare Associations (Ministry of Health and Care Services, 2008). Overall, the resources available for counseling and health services vary considerably across campuses, and this is true both in Norway and internationally (Hunt and Eisenberg, 2010; Nedregård and Olsen, 2014).

\section{Strengths and Limitations}

This study has several strengths. SHoT 2014 is a survey with a wide scope and a high number of participants. The total database includes responses from 13,663 students (Nedregård and Olsen, 2014). The questionnaire in SHoT 2014 is a revised version of the one used in 2010, and mainly validated instruments have been used in the design of the form. In addition, there is little missing data among the responses. For the variable regarding symptoms of mental health problems, 6 respondents did not answer the question and for academic self-efficacy and study progress, $59 \mathrm{did}$ not answer the question.

At the same time, some limitations must be kept in mind in the interpretation of the results. A response rate of $31 \%$ in a questionnaire survey is usually regarded as low, which increases the risk of systematic bias (Ringdal, 2007). According to the conductors of SHoT, students' response rate to questionnaires is lower than the rate for other groups (Nedregård and Olsen, 2014). In Internet-based surveys conducted among students, it is therefore not unusual for the response rate to be around 25\% (Nedregård and Olsen, 2014). Fortunately, those who answered are relatively representative in terms of gender and age distribution compared to the drawn total sample. In addition, this is a cross-sectional study, and we cannot draw conclusions about cause-effect mechanisms (Ringdal, 2007). In simple terms, symptoms of severe mental health problems may lead to low academic self-efficacy, but they can also be a consequence of low academic self-efficacy. The same applies to the association between symptoms of severe mental health problems and poor study progress.

\section{CONCLUSION}

This study confirms previous findings regarding the relatively high occurrence of mental problems among students and low levels of help-seeking (Tyssen et al., 2004; Zivin et al., 2009; Verouden et al., 2010; Eisenberg et al., 2012). The strong association between psychological distress and academic selfefficacy has also been described in previous studies (Karademas and Kalantzi-Azizi, 2004; Byrd and McKinney, 2012), yet the causal pathways and underpinning mechanisms are not fully understood.

First, we suggest that future studies should assess students' health prior to study start and follow them up with repeated measurements and qualitative interviews. This methodology could provide useful knowledge about mental health problems and how they arise and influence academic self-efficacy and study progress. Second, counseling and health services should be easily available and offered on campus, to facilitate and increase mental health literacy and help seeking - both represent key challenges across societal and health care settings. More specifically, psychoeducational interventions, counseling, guidance and treatment, group initiatives, stigma reducing, and health-promoting measures could be carried out and evaluated in the university setting. Finally, research that combines educational and psychological theory in higher education might contribute further to a more complete understanding of the associations between mental health, academic self-efficacy and study progress.

\section{AUTHOR CONTRIBUTIONS}

KG, ES, and OB contributed substantially to the conceptualisation and design of the study. KG and ES performed the statistical analysis. KG wrote the first draft of the article. ES and $\mathrm{OB}$ revised it critically for important intellectual content. All authors read and approved the final version of the manuscript and contributed to the interpretation of the data.

\section{FUNDING}

This study was funded by our employer, Nord University, Norway (through our ordinary salaries, as there were no extra costs associated with data collection). 


\section{REFERENCES}

Adalf, E. M., Gliksman, L., Demers, A., and Newton-Taylor, B. (2001). The prevalence of elevated psychological distress among Canadian undergraduates: findings from the 1998 Canadian campus survey. J. Am. Coll. Health 50, 67-72. doi: 10.1080/07448480109596009

Amdam, S., and Vrålstad, S. (2012). Levekårsundersøkelsen om Helse, Omsorg og Sosial Kontakt 2012. Oslo: Statistics Norway.

Andrews, B., and Wilding, J. M. (2004). The relation of depression and anxiety to life-stress and achievement in students. Br. J. Psychol. 95, 509-521. doi: 10.1348/0007126042369802

Astin, A. (1993). What matters in college? Lib. Educ. 79, 4-12.

Bandura, A. (1986). Social Foundations of Thought and Action: A Social Cognitive Theory. Englewood Cliffs, NJ: Prentice Hall.

Bandura, A. (1997). Self-Efficacy: The Exercise of Control. New York, NY: W.H. Freeman.

Bewick, B., Koutsopoulou, G., Miles, J., Slaa, E., and Barkham, M. (2010). Changes in undergraduate student's psychological well-being as they progress through university. Stud. High. Educ. 35, 633-645. doi: 10.1080/03075070903216643

Brown, S. D., Tramayne, S., Hoxha, D., Telander, K., Fan, X., and Lent, R. (2008). Social cognitive predictors of college students' academic performance and persistence: a meta-analytic path analysis. J. Vocat. Behav. 72, 298-308. doi: 10.1016/j.jvb.2007.09.003

Byrd, D. R., and McKinney, K. J. (2012). Individual, interpersonal, and institutional level factors associated with the mental health of college students. J. Am. Coll. Health 60, 185-193. doi: 10.1080/07448481.2011.584334

Choi, N. (2005). Self-efficacy and self-concept as predictors of college students' academic performance. Psychol. Sch. 42, 197-205.

Cook, R., Bewick, B. M., Barkham, M., Bradley, M., and Audin, K. (2006). Measuring, monitoring and managing the psychological well-being of first year university students. Br. J. Guid. Couns. 34, 505-517. doi: 10.1002/pits.20048

Deane, F. P., Leathern, J., and Spicer, J. (1992). Clinical norms, reliability and validity for the hopkins symptom checklist-21. Aust. J. Psychol. 44, 21-25. doi: 10.1080/03069880600942624

Derogatis, L. R., Lipman, R. S., Rickels, K., Uhlenhuth, E. H., and Covi, L. (1974). The hopkins symptom checklist (HSCL): a self-report symptom inventory. Behav. Sci. 19, 1-15. doi: 10.1080/00049539208260158

Dinther, M. V., Dochy, F., and Segers, M. (2011). Factores affecting students'selfefficacy in higher education. Educ. Res. Rev. 6, 95-108. doi: 10.1002/bs. 3830190102

Eisenberg, D., Golberstein, E., and Hunt, J. B. (2009). Mental health and academic success in college. J. Econ. Anal. Policy 9:40. doi: 10.1016/j.edurev.2010.10.003

Eisenberg, D., Hunt, J., and Speer, N. (2012). Help-seeking for mental health on college campuses: review of evidence and next steps for research and practice. Harv. Rev. Psychiatry 20, 222-231. doi: 10.3109/10673229.2012.712839

Eisenberg, D., Hunt, J., and Speer, N. (2013). Mental health in American colleges and universities: variation across student subgroups and across campuses. $J$. Nerv. Ment. Dis. 201, 60-67. doi: 10.1097/NMD.0b013e31827ab077

Fenollar, P., Romàn, S., and Cuestas, P. J. (2007). University students' academic performance: an integrative conceptual framework and empirical analysis. $\mathrm{Br}$. Psychol. Soc. 77(Pt 4), 873-891. doi: 10.1348/000709907X189118

Fong, C. J., Davis, C. W., Kim, Y., Kim, Y. W., Marriott, L., and Kim, S. Y. (2017). Psychological factors and community college student success: a meta-analytic investigation. Rev. Educ. Res. 87, 388-424. doi: 10.3102/0034654316653479

Gore, P. A. Jr. (2006). Academic self-efficacy as a predictor of college outcomes: two incremental validity studies. J. Career Assess. 14, 92-115. doi: 10.1177/ 1069072705281367

Heinrich, L. M., and Gullone, E. (2006). The clinical significance of loneliness: a literature review. Clin. Psychol. Rev. 26, 695-718. doi: 10.1016/j.cpr.2006.04.002

Hoffmann, C., McFarland, B. H., Kinzie, J. D., Bresler, L., Rakhlin, D., Wolf, S., et al. (2006). Psychological distress among recent Russian immigrants in the United States. Int. J. Soc. Psychiatry 52, 29-40. doi: 10.1177/0020764006061252

Hovdhaugen, E., and Aamodt, P. O. (2009). Learning environment: relevant or not to students' decision to leave university. Qual. High. Educ. 15, 177-189. doi: 10.1080/13538320902995808

Hunt, J., and Eisenberg, D. (2010). Mental health problems and help-seeking behavior among college students. J. Adolesc. Health 46, 3-10. doi: 10.1016/j. jadohealth.2009.08.008
Ibrahim, A. K., Kelly, S. J., Adams, C. E., and Glazebrook, C. (2013). A systematic review of studies of depression prevalence in university students. J. Psychiatr. Res. 47, 391-400. doi: 10.1016/j.jpsychires.2012.11.015

Jerusalem, M., and Schwartzer, R. (1992). "Self-efficacy as a resource factor in stress appraisal processes," in Self-Efficacy: Thought Control of Action, ed. R. Schwartzer (Washington, DC: Hempshire), 195-236.

Karademas, E. C., and Kalantzi-Azizi, A. (2004). The stress process, self-efficacy expectations, and psychological health. Pers. Individ. Differ. 37, 1033-1043. doi: 10.1016/j.paid.2003.11.012

Kessler, R. C., Berglund, P., Demler, O., Jin, R., and Walters, E. E. (2005). Lifetime prevalence and age-of-onset distributions of DSM-IV disorders in the national comorbidity survey replication. Arch. Gen. Psychiatry 62, 593-602. doi: 10.1001/ archpsyc.62.6.593

Keyes, C. L. M., Eisenberg, D., Perry, G., Dube, S. R., Kroenke, K., and Dhingra, S. S. (2012). The relationship of level of positive mental health with current mental disorders in predicting suicidal behavior and academic impairment in college students. J. Am. Coll. Health 60, 126-133. doi: 10.1080/07448481.2011.608393

Ministry of Health and Care Services (2008). Rapport: Psykisk Helsetjeneste for Studenter. Available at. https://www.regjeringen.no/globalassets/upload/hod/ sha/psykiskhelsetjenesteweb.pdf

Mouanoutoua, V. L., and Brown, L. G. (1995). Hopkins symptom checklist-25, Hmong version: a screening instrument for psychological distress. J. Pers. Assess. 64, 376-383. doi: 10.1207/s15327752jpa6402_16

Mykletun, A., Knudsen, A. K., and Mathiesen, K. S. (2009). Psykisk Helse i Norge: Et Folkehelseperspektiv. Available at: www.fhi.no/globalassets/dokumenterfiler/ moba/pdf/rapport-20098-pdf-.pdf

Nedregård, T., and Olsen, R. (2010). Studentenes Helse- Og Trivselsundersøkelse SHOT 2010. Available at: https://sis.uis.no/wp-content/uploads/2014/05/shot_ 2010_rapport.pdf.

Nedregård, T., and Olsen, R. (2014). Studentenes Helse- Og Trivselsundersøkelse SHOT 2014. Available at: http://www.vtbergen.no/wp-content/uploads/2013/ 10/VT0614_6214_SHoT2014.pdf

Nerdrum, P., Rustøen, T., and Rønnestad, M. H. (2009). Psychological distress among nursing, physiotherapy and occupational therapy students: a longitudinal and predictive study. Scand. J. Educ. Res. 53, 363-378. doi: 10.1080/ 00313830903043133

Nyman, E., Miettunen, J., Freimer, N., Joukamaa, M., Maki, P., Ekelund, J., et al. (2010). Impact of temperament on depression and anxiety symptoms and depressive disorder in a population-based birth cohort. J. Affect. Disord. 131, 393-397. doi: 10.1016/j.jad.2010.12.008

Pajares, F., and Schunk, D. H. (2006). "Self and self-belief in psychology and education: an historical perspective," in Improving Academic Achievement, ed. J. Aronson (New York, NY: Academic Press).

Pascarella, E. T., and Terenzini, P. T. (2005). How College Affects Students: A Third Decade of Research. San Francisco, CA: Jossey-Bass.

Pritchard, M. E., and Wilson, G. S. (2003). Using emotional and social factors to predict student success. J. Coll. Stud. Dev. 44, 18-28. doi: 10.1353/csd.2003.0008

Quinn, N., Wilson, A., MacIntyre, G., and Tinklin, T. (2009). "People look at you differently": students' experience of mental health support within higher education. Br. J. Guid. Couns. 37, 405-418. doi: 10.1080/03069880903161385

Reason, R. D., Terenzini, P. T., and Domingo, R. J. (2006). Developing academic competence in the first year of college. Res. High. Educ. 47, 149-175. doi: $10.1007 /$ s11162-005-8884-4

Reavley, N., and Jorm, A. F. (2010). Prevention and early intervention to improve mental health in higher education students: a review. Early Interv. Psychiatry 4, 132-142. doi: 10.1111/j.1751-7893.2010.00167.x

Regehr, C., Glancy, D., and Pitts, A. (2013). Interventions to reduce stress in university students: a review and meta-analysis. J. Affect. Disord. 148, 1-11. doi: 10.1016/j.jad.2012.11.026

Rice, K. G., Leever, B. A., Christopher, J., and Porter, D. (2006). Perfectionism, stress and social (dis)connection: a short-term study of hopelessness, depression, and academic adjustment among honors students. J. Couns. Psychol. 53, 524-534. doi: 10.1037/0022-0167.53.4.524

Richardson, M., Abraham, C., and Bond, R. (2012). Psychological correlates of university students' academic performance: a systematic review and metaanalysis. Psychol. Bull. 138, 353-387. doi: 10.1037/a0026838

Ringdal, K. (2007). Enhet og Mangfold Samfunnsvitenskapelig Forskning og Kvantitativ Metode, 2nd Edn. Bergen: Fagbokforlaget. 
Robbins, S. B., Lauver, K., Le, H., Davis, D., Langley, R., and Carlstrom, A. (2004). Do psychosocial and study skill factors predict college outcomes? A meta-analysis. Psychol. Bull. 130, 261-288. doi: 10.1037/0033-2909.130.2.261

Roberts, R., Golding, J., Towell, T., and Weinreb, I. (1999). The effects of economic circumstances on British students' mental and physical health. J. Am. Coll. Health 48, 103-109. doi: 10.1080/07448489909595681

Roness, A., Mykletun, A., and Dahl, A. A. (2005). Help-seeking behavior in patients with anxiety disorder and depression. Acta Psychiatr. Scand. 111, 51-58. doi: 10.1111/j.1600-0447.2004.00433.x

Salzer, M. S. (2012). A comparative study of campus experiences of college students with mental illnesses versus a general college sample. J. Am. Coll. Health 60, 1-7. doi: 10.1080/07448481.2011.552537

Stallmann, H. M. (2008). Prevalence of psychological distress in university students: implications for service delivery. Aust. Fam. Physician 37, 673-677.

Stanley, N., and Manthorpe, J. (2001). Responding to students' mental health needs: impermeable systems and divers users. J. Ment. Health 10, 41-52. doi: $10.1080 / 09638230020023606$

Stewart-Brown, S., Evans, J., Patterson, S., Peterson, S., Doll, H., Balding, J., et al. (2000). The health of students in institutes of higher education: an important and neglected public health problem? J. Public Health Med. 22, 492-499. doi: $10.1093 /$ pubmed/22.4.492

Storrie, K., Ahren, K., and Tuckett, A. (2010). A systematic review: students with mental health problems - a growing problem. Int. J. Nurs. Pract. 16, 1-6. doi: 10.1111/j.1440-172X.2009.01813.x

Svanum, S., and Zody, Z. B. (2001). Psychopathology and college grades. J. Couns. Psychol. 48, 72-76. doi: 10.1037/0022-0167.48.1.72

Tambs, K., and Moum, T. (1993). How well can a few questionnaire items indicate anxiety and depression? Acta Psychiatr. Scand. 87, 364-367.

Tinto, V. (1993). Leaving College, 2nd Edn. Chicago, IL: University of Chicago Press.

Tinto, V. (2006). Research and practice of student retention: what next? J. Coll. Stud. Ret. 8, 1-19. doi: 10.2190/4YNU-4TMB-22DJ-AN4W

Tyssen, R., Røvik, J. O., Vaglum, P., Grønvold, N. T., and Ekeberg, Ø (2004). Help-seeking for mental health problems among young physicians: is it the most ill that seeks help? Soc. Psychiatry Psychiatr. Epidemiol. 39, 989-993. doi: 10.1007/s00127-004-0831-8
Vaez, M., and Laflamme, L. (2008). Experienced stress, psychological symptoms, self-rated health and academic achievement: a longitudinal study of Swedish university students. Soc. Behav. Pers. 36, 183-196. doi: 10.2224/sbp.2008.36.2. 183

Veijola, J., Jokelainen, J., Laksy, K., Kantojarvi, L., Kokkonen, P., Jarvelin, M. R., et al. (2003). The hopkins symptom checklist-25 in screening DSM-III-RaxisI disorders. Nord. J. Psychiatry 57, 119-123. doi: 10.1080/0803948031000 0941

Verouden, N. W., Vonk, P., and Meijman, F. J. (2010). Context guides illnessidentity: a qualitative analysis of Dutch university students' non-help-seeking behavior. Int. J. Adolesc. Med. Health 22, 307-320. doi: 10.1515/IJAMH.2010. 22.2.307

Vuong, M., Brown-Welty, S., and Tracz, S. (2010). The effects of self-efficacy on academic success of first-generation college sophomore students. J. Coll. Stud. Dev. 51, 50-64. doi: 10.1353/csd.0.0109

Winokur, A., Winokur, D. F., Rickels, K., and Cox, D. S. (1984). Symptoms of emotional stress in family planning service: stability over a four-week period. Br. J. Psychiatry 144, 395-399. doi: 10.1192/bjp.144.4.395

Zajacova, A., Lynch, S. M., and Espenshade, T. J. (2005). Self-efficacy, stress and academic success in college. Res. High. Educ. 46, 677-706. doi: 10.1007/s11162004-4139-z

Zivin, K., Eisenberg, D., Gollust, S. E., and Golberstein, E. (2009). Persistence of mental health problems and needs in a college student population. J. Affect. Disord. 117, 180-185. doi: 10.1016/j.jad.2009.01.001

Conflict of Interest Statement: The authors declare that the research was conducted in the absence of any commercial or financial relationships that could be construed as a potential conflict of interest.

Copyright (c) 2019 Grøtan, Sund and Bjerkeset. This is an open-access article distributed under the terms of the Creative Commons Attribution License (CC BY). The use, distribution or reproduction in other forums is permitted, provided the original author(s) and the copyright owner(s) are credited and that the original publication in this journal is cited, in accordance with accepted academic practice. No use, distribution or reproduction is permitted which does not comply with these terms. 